\title{
POLÍTICAS DE CONTENÇÃO DE DESMATAMENTO, PRODUÇÃO E MERCADO DE TERRAS NA AMAZÔNIA: UM ENSAIO SOBRE A ECONOMIA LOCAL DO SUDESTE PARAENSE USANDO CONTAS SOCIAIS ALFA $\left(\mathrm{CS}^{\alpha}\right)$
}

\author{
Francisco de ASSIS Costa* \\ NAEA/UFPA
}

Submetido em Julho 2009; aceito em Julho 2011

\section{Resumo}

A discussão atual sobre a emissão de carbono associada ao uso agropecuário da terra em prejuízo de florestas se ressente de uma visão sistêmica, no que se refere aos fluxos econômicos propriamente, e suas interações, no que tange ao ambiente institucional que os garante. Dado que os esquemas de compensação implicam a entrada e saída de recursos em contextos econômicos amplos e sistêmicos, fundamental é discutir qual o resultado final desses fluxos sobre as condições gerais de reprodução das economias locais. As questões básicas são: a) como tais políticas poderão, a partir dos setores rurais, afetar a demanda final efetiva e, por essa via, o valor da produção e as variáveis de valor adicionado de toda a economia e b) como as variações na economia afetam as formas de uso da base natural e, portanto, o desmatamento. No que se refere às instituições, o artigo dá especial ênfase às que definem o mercado de terras, porque nele encontra o cerne de questões vitais para o que se discute. $\mathrm{O}$ artigo utiliza um modelo ascendente de geração de matrizes de insumo-produto para a economia local do Sudeste Paraense, incorpora nela um balanço de carbono dos setores da produção rural, encontra os multiplicadores e simula quatro situações de politica de contenção de desmatamento e redução das emissões de gases poluentes. A conclusão principal do artigo é que se faz necessário pensar políticas de contenção de desmatamento ligadas indissociavelmente a políticas de produção - a serem operadas por mecanismos que façam convergir as decisões dos agentes com perspectivas macro de desenvolvimento: local, endógeno e sustentável.

\footnotetext{
* Professor Associado do Núcleo de Altos Estudos Amazônicos - NAEA/UFPA. Visiting Fellow do Centre for Brazilian Studies, University of Oxford. Pesquisador Associado da RedeSist, IE/UFRJ.

Endereço para contato: Universidade Federal do Pará - Núcleo de Altos Estudos Amazônicos e Programa de Pós-Graduação em Economia. Campus Universtário do Guamá, setor Profissional - CEP: 66000000

E-mail: francisco_de_assis_costa@yahoo.com.br - Parte desse texto foi redigida no período em que o autor se encontrava Visiting Fellow do Centre for Brazilian Studies, University of Oxford. Sem o apoio acadêmico e financeiro do CBS e do CNPq, e sem a boa vontade da Companhia Vale do Rio Doce em fornecer seus dados, este trabalho não teria sido possível. A pesquisa sobre o mercado de terras teve incentivo do Centro de Estudos e Gestão Estratégica, CGEE. A todos o autor agradece encarecidamente.
} 


\section{Palavras-Chave}

amazônia, balanço de carbono, economia local, sudeste paraense, contenção do desmatamento

Classificação JEL

Q52, R15

\section{Abstract}

The current discussion on avoiding carbon emission associated to agricultural use of land needs a more systemic approach, whether in regard to the economic flows properly and their interactions, whether in terms of the institutional environment that ensures them. Given that avoiding deforestation schemes implicate resources input-output throughout local economies and broader economic context, it seems fundamental to discuss what are the final impacts of those flows. The basic questions are: a) how such policies, starting from the rural sectors, will affect final demand, the value of the production and the variables of value added all over the economy and b) how variations in the economy affect the forms of use of natural resources and, therefore, deforestation itself. Related to institutions, the article puts special emphasis on defining the market for land, because it is the core of vital issues. The article uses an ascending model to generate input-output matrices for local economies based on primary products, where works a market for land, incorporates an algorithm of carbon balance, finds the multipliers of the economy of Southeastern Pará and simulates four situations of policies on avoiding deforestation. The main conclusion is that policies for avoiding deforestation will probably have a hard time if not part of macro development policy on local level.

JEL classification codes: Q52, R15

Keywords: amazonia, amazon region, carbon balance, local economy, south-west of Pará, avoiding deforestation

\section{Introdução}

A discussão atual sobre a emissão de carbono associada ao uso agropecuário da terra em prejuízo de florestas se ressente de uma visão sistêmica - na qual o "lugar" e o "sentido" dos processos em andamento sejam devidamente considerados. Quando, para o equacionamento das estratégias de mitigação, são tratadas as formas de contenção ou controle do desmatamento, por exemplo, o foco tem sido microeconômico e genérico, dominando uma perspectiva de agentes homogêneos, cujas decisões se orientariam por médias estrutural (dos sistemas e de produção) e espacialmente (das economias - arranjos produtivos e polos - locais) descontextualizadas. De modo que, 
o que se considera base de compensação é a remuneração líquida por produto obtida nesse nível de abstração e formalismo, após descontados do total de receita todos os custos, inclusive os custos do trabalho. E se buscam médias de médias, num processo que ao final se arroga oferecer expressões válidas para amplos contextos - regionais e, mesmo, nacionais - em tempo indefinido.

Este é o procedimento de Grieg-Gran (2006), principal fonte analítica do Stern Review, quando se refere aos custos de um programa de "evitação" compensada de desflorestamento em nível mundial.

Dois problemas principais advêm dessa leitura baseada em agente-padrão: a não consideração, ou a consideração insuficiente dos efeitos meso e macrossistêmicos derivados do contexto econômico e institucional onde operam, e o não tratamento da diversidade de racionalidades e estruturas relevantes que conformam os fundamentos microeconômicos da dinâmica em questão.

O próprio Stern (2007) reconhece parte da insuficiência da abordagem - no que se refere à não consideração de efeitos meso e macroeconômicos da produção "evitada". Reconhecendo a falta, contudo, Stern reduz suas consequências: "Research commissioned by the Review, suggests that the direct yield from land converted to farming, including proceeds from the sale of timber, are equivalent to less than $\$ 1$ per tone of $\mathrm{CO}_{2}$ in many areas currently losing forest, and usually well below $\$ 5$ per tone. The opportunity costs to national GDP would be somewhat higher, as these would include value added activities in country and export tariffs." (Stern, 2007:607. Grifos meus).

Mais recentemente, Angelson et alii (2009), avaliando as opções para o programa internacional Reducing Emissions from Deforestation and Forest Degradation (REDD) em relatório para o governo da Noruega, reconhecem também parte dos fenômenos sistêmicos - daqueles relativos à transferência de atividades contidas em um ponto do sistema, para outro: os "vazamentos". Com efeito, utilizando o OSIRIS (Open Source Impacts of REDD Incentives Spreadsheet, um processador do modelo de equilíbrio geral de mercado de uma única commodity em um período, adaptado de Murray, McCarl e Lee (2004)), os autores fazem uma análise de vazamentos internacionais como peça de avaliação dos riscos das políticas de REDD, cuja efetividade no plano global poderia ser solapada pela transferência das atividades contidas em países integrantes, para países não integrantes dos acordos. A commodity do modelo constitui-se em um índice composto do rendimento líquido da produção agrícola e madeireira por hectare desflorestado - uma proxy, como no caso do Stern Review, do custo de oportunidade privado dos usos da terra na fronteira agrícola que afrontam a floresta. 
A ênfase no custo de oportunidade privado impede, às abordagens citadas, o tratamento para fenômenos, cuja importância tem sido realçada por longa tradição do pensamento econômico sobre crescimento e desenvolvimento. Enquanto Stern reduz a um somewhat, Angelson e associados simplesmente desconsideram os efeitos sistêmicos dos impactos multiplicadores (Keynes, 1976) derivados daquilo que Myrdal (1957), Hirschman (1958) e Perroux (1965) consagraram na literatura econômica como fenômenos de "causação circular e cumulativa" próprios às "concatenações para frente e para trás" que mobilizam as economias ao crescimento e, mesmo, ao desenvolvimento. Maior a falta quando se considera, como fazem hoje os autores do desenvolvimento endógeno, em particular Romer (1986), Krugman (1995) e Arthur (1994), que "vazamentos", tanto quanto "polarizações", são expressões das interações desequilibradas entre "forças centrífugas" e "centrípetas" inerentes aos processos de desenvolvimento nas sociedades modernas, cuja compreensão exige o tratamento de sua dimensão local (Fujita, Krugman, Venebles, 2002; Diniz, Lemos, 2005).

Por outro lado, a preocupação com a sustentabilidade do desenvolvimento tem sido introduzida na problemática por viés "niilista" e "estático"; eis que, em perspectiva política, saldos negativos dos balanços de $\mathrm{CO}_{2}$ (emissões menos sequestro de carbono) das atividades agrícolas seriam necessariamente resultados de "não produção". Torna-se urgente que se internalizem nos modelos percepções mais complexas dos sistemas agrícolas, que suportem uma perspectiva "positiva" e "dinâmica" em relação à produção. Tal noção, aliás, vem ganhando terreno. Antes vistos (quase) exclusivamente do lado da emissão de poluentes e redução da biodiversidade - i.e. do lado da demanda na formação dos novos mercados de bens ambientais, na condição de formadores de necessidades de sequestro de carbono e reposição da complexidade biológica -, um subconjunto de sistemas baseados em culturas perenes e em composições agro-florestais é reconhecido pelo Stern Review como potencialmente consistentes com a conservação florestal no contexto de estratégias para reduzir emissões (Stern, 2007: 603-621). Reconhece-se, assim, que tais atividades, reduzindo a pressão sobre as florestas e criando mecanismo de absorção líquida de carbono, podem expandir a oferta e, em consequência, baratear o bem ambiental em si - a estabilização ou reversão das mudanças climáticas - tornando mais custoefetivas as estratégias de mitigação.

Tais considerações nos levam de imediato a indagar, no ensejo de políticas de contenção de desmatamento e seus efeitos sobre emissões líquidas de $\mathrm{CO}_{2}$ : a) Quanto, exatamente, seria o somewhat adicionado nas cadeias a serem desmontadas e, uma vez que a perspectiva de compensação exclui salários, quais as implicações na demanda efetiva das economias onde operarão os esquemas de "evitação"?; b) Antes de "vazamentos" internacionais, há "vazamentos" em nível intranacional, mais precisamente local/regional, por mobilidade de agentes?; c) Por outro lado, o quão consistentes são as 
atividades promissoras, na perspectiva das emissões, com dinâmicas reais de expansão das economias em que se inserem?; d) Qual o contexto institucional operante, que tem sistemicamente garantido o status quo, a qual a nova política deve confrontar? Terá ela capacidade para isso?

Essas perguntas, pontuais, nos levam a indagações mais abrangentes, organizadas pelo estado atual das discussões sobre desenvolvimento, sustentabilidade e configuração espacial - é dizer sobre as relações entre economia, sociedade e natureza na Amazônia, que motivam nossos esforços neste projeto. A indagação principal é: dado que os esquemas de compensação (por não produção ou para produção limpa) implicam a entrada e saída de recursos em contextos econômicos amplos e sistêmicos, qual o resultado final desses fluxos sobre as condições gerais de reprodução das economias, sobre suas variáveis fundamentais de renda e emprego, sobre suas relações com a base natural que a fundamenta e, portanto, sobre sua capacidade endógena de evoluir superando as próprias forças que produzem o desmatamento e as emissões? Mais precisamente: a) como tais políticas poderão, a partir dos setores rurais, afetar a demanda final efetiva e, por essa via, o valor da produção e as variáveis de valor adicionado de toda a economia?; b) Como isso pode afetar sua produtividade macroeconômica?; c) Como as variações na economia afetam as formas de uso da base natural e, portanto, o desmatamento e as emissões a elas associadas?; d) Como essa base natural é posta à disposição dos agentes - isto é, como o mercado de terras, enquanto mecanismo institucional chave, atua nesse contexto?

Adiante procuramos respostas para estas questões a partir da análise da economia de uma região crítica nas dinâmicas recentes de ocupação da Amazônia - a área compreendida pela mesorregião sudeste paraense, no estado do Pará. Para tanto, será utilizada uma matriz de insumo-produto gerada por metodologia de cálculo ascendente capaz de captar os fundamentos da economia agrária que subjaz às emissões de carbono e situá-los no contexto amplo da economia local de base primária, do que se inclui a produção mineral e seus desdobramentos urbanos - industriais e comerciais, por um lado, regionais e nacionais, por outro. De particular importância para o tratamento adequado das questões que nos importam é a consideração do mercado de terras que em última instância fundamenta o modo particular como essa economia tem evoluído.

O artigo está organizado em cinco capítulos, além desta introdução; no capítulo 2 apresentamos rapidamente a região estudada; no capítulo 3 apresentaremos a metodologia utilizada; no capítulo 4 serão discutidos os resultados obtidos à luz do questionamento acima apresentado; ao final, a título de conclusão, teceremos considerações e indicações para políticas e futuros estudos. 


\section{O Sudeste Paraense e suas Principais Estruturas de Produção Primária}

O sudeste paraense compõe-se dos municípios de Marabá, Parauapebas, Curionópolis, Ourilândia do Norte, Tucumã, Eldorado dos Carajás, Canaã dos Carajás, São Felix do Xingu, São João do Araguaia, Brejo Grande do Araguaia, Bom Jesus do Tocantins, Palestina do Pará, São Domingos do Araguaia, Pau D’Arco, Redenção, Rio Maria, Xinguara, Conceição do Araguaia, Paragominas, Tucurui, Jacundá, Itupiranga, São Domingos do Capim, Rondom do Pará, Dom Eliseu, Ulianópolis, Goianésia do Pará, Novo Repartimento, Breu Branco e Nova Ipixuna.

Esta tem sido uma região de extraordinária dinâmica. Lá se alocaram os grandes projetos pecuários financiados pela SUDAM desde meados dos anos sessenta, os quais confrontaram frentes de expansão da agricultura familiar, inicialmente espontâneas nos anos cinquenta, sessenta e setenta, depois induzidas nos anos oitenta e noventa por dinâmicas institucionais - como os assentamentos da reforma agrária - e econômicas como a ocorrência de grandes projetos minerais e de surtos garimpeiros. Como partes do processo ocorreram transformações estruturais importantes, que de um lado implicaram a transformação de agentes mercantis e extrativistas da economia da madeira e da Castanha-do-Pará em pecuaristas de médio e grande porte; de outro lado, reforçaram o papel dos centros urbanos e suas bases rurais locais na logística de novos setores econômicos condicionados pela formação da economia mineral, posto que se trata da principal área de atuação da Companhia Vale do Rio Doce no Pará, onde explora seu sistema norte de metais ferrosos com base em Carajás e onde expandirá e diversificará nos próximos seis anos de modo vigoroso sua produção.

Síntese do processo por que passa a mesorregião nas últimas três décadas, a taxa de crescimento demográfico foi da ordem de $8 \%$ a.a. até início dos anos noventa, reduzindo para 3,3\% a.a. ao longo dessa década, no final da qual a população total atinge 1,2 milhões de habitantes, dos quais, no ano de 2000, 759.575 moravam em cidades e 432.560 na zona rural. A isso se associa uma taxa de incorporação de terras para uso agropecuário igualmente explosiva nas primeiras décadas, amainando para 3,7\% a.a. entre 1995 e 2004, período em que estimamos um salto de uma área de 10,2 milhões de hectares ligados à produção agropecuária no primeiro, para quase 12 milhões de hectares no último ano. O balanço líquido (emissão menos sequestro) de carbono em 2004 deverá ter sido de 293,2 milhões de toneladas, representando nada menos que $34,6 \%$ das emissões líquidas de $\mathrm{CO}_{2}$ equivalente em toda a Região Norte, no mesmo ano (conf. Costa, 2007). 


\section{O Modelo de Contas Sociais Ascendentes Alfa (CS $\left.{ }^{\alpha}\right)$ e sua Aplicação ao Sudeste Paraense}

Costa (2008d e 2006) utiliza um modelo de insumo-produto que denomina Contas Sociais Alfa $\left(C S^{\alpha}\right)$ para descrever a economia do sudeste paraense. Trata-se de metodologia ascendente porque baseada nos parâmetros e indicadores de cada produto que compõe os setores originários e fundamentais, obtidas as estatísticas de produção no nível mais irredutível possível de uma economia local. Tais "setores originais" são tratados como "setores alfa": ponto inicial, lugar de partida de tudo o mais. No trajeto dos produtos advindos dos "setores alfa" são definidos parametricamente os setores derivados, tratados como "Setores Beta", os quais são ajustados a três níveis diferentes: o nível local $(\beta \mathrm{a})$, o nível estadual $(\beta \mathrm{b})$ e o nível nacional $(\beta \mathrm{c})$.

Porque consegue explicitar qualquer configuração estrutural capaz de ser delimitada nos bancos de dados disponíveis, a metodologia apresenta a economia local em questão de uma maneira particularmente interessante para nossos propósitos aqui. Em artigos recentes foram discutidas matrizes que situavam as estruturas fundamentais do setor rural na região, suas interações com outros setores de base primária, como o da exploração mineral, e com a economia urbana local, estadual e nacional (Costa, 2009b; 2008). O mesmo autor sugere em outro lugar um modelo de cálculo de emissão e sequestro de $\mathrm{CO}_{2}$ associados às dinâmicas diferenciadas dessas estruturas rurais (Costa, 2009a).

Utilizaram-se aqui resultados da aplicação combinada desses dois modelos. Na aplicação do modelo de insumo-produto incluiu-se, entretanto, à diferença dos trabalhos citados, o mercado de terras, como se discutirá detalhadamente adiante. Por outro lado, instrumentou-se o modelo para que aplique, para os "setores alfa" ligados à produção rural, o mesmo algoritmo utilizado para o cálculo do balanço de carbono já mencionado. Note-se, porém, que neste estudo não se obtiveram valores do balanço para o "setor alfa" não rural (a mineração) nem para os "setores beta", porque o propósito é focar os setores mais visados relativamente às emissões associadas ao desmatamento e uso da terra.

\section{A Matriz de Insumo-Produto e os Multiplicadores da Economia do Sudeste Paraense}

No presente exercício configurou-se a economia do sudeste paraense a partir da produção de três setores alfa de produção primária: dois da produção rural e um de produção mineral. As bases agrárias do sudeste paraense resultam de um processo de apropriação fundiária que se fez por agentes com características sociológicas distintas, às quais se 
tem atribuído racionalidades econômicas também diferenciadas. Na região, tais sujeitos estabeleceram estruturas próprias a partir de formas peculiares de privatização da terra e dos recursos da natureza e das diferentes relações sociais e técnicas engendradas na exploração da terra e dos recursos da natureza (Costa, 2009d).

São duas as estruturas básicas em torno das quais se organizam a produção e a vida rurais na Região: a unidade de produção camponesa e o estabelecimento patronal. A unidade de produção camponesa caracteriza-se por ter na família seu parâmetro decisivo: seja como definidora das necessidades reprodutivas, que estabelecem a extensão e a intensidade do uso da capacidade de trabalho de que dispõe, seja como determinante no processo de apropriação de terras nas sagas de fronteira. Precisamente esse critério fundamentou a distinção dos estabelecimentos no banco de dados que aqui utilizamos: aqueles nos quais a força de trabalho familiar supera 50\% do total da força de trabalho aplicada foram tratados como "camponês". Os demais, como "patronal" (conf. Veiga, 1991a e b): empresas rurais e fazendas para as quais a mediação do mercado de trabalho é condição de existência, condicionando fortemente suas características técnicas - de apropriação e uso da natureza.

No que se refere à produção mineral, o banco de dados contém as informações relativas às plantas da Companhia Vale do Rio Doce operando na Região no ano de 2004 (informações prestadas pela CVRD ao autor).

\section{A. A Economia do Sudeste Paraense, seus Multiplicadores de Renda e as Emissões Líquidas de Carbono}

A economia do Sudeste Paraense descrita na Tabela 1 para 2004 engloba as relações da economia local de base primária e seus desdobramentos em nível local (setores $\beta \mathrm{a}$ ), estadual (setores $\beta \mathrm{b}$ ) e nacional (setores $\beta \mathrm{c}$ ). Nas suas dimensões absolutas essa economia gerou, em 2004, um valor adicionado total (VA) de R \$ 11,2 bilhões a partir de um nível global de atividade expresso no valor bruto da produção (VBP) total de R\$ 26,22 bilhões. Foi responsável por um volume de ocupações (E) de 372,3 mil, associado a uma massa global de salários (S) de $\mathrm{R} \$ 1,83$ bilhões de reais, uma margem bruta de remuneração de capital (L) de R \$ 8,06 bilhões e impostos (I) no montante de R \$1,3 bilhões. Comparando com os valores apresentados em Costa (2008c) verifica-se que a inclusão do mercado de terras acresceu o VA e o VBP, respectivamente, em R $\$ 185,3$ e R \$ 465,4 milhões - 1,81\% e 1,68\% de acréscimo. O número de ocupações, a massa de salários, a margem bruta de remuneração do capital e os impostos devem, por seu turno, à inclusão do mercado de terras, parcelas correspondentes a, respectivamente, $1,11 \%, 1,3 \%, 1,76 \%$ e $1,76 \%$ de acréscimo. 
A economia local participou com $61 \%$ do VA total: $73 \% \%$ disso nos setores de produção (setores $\alpha$ ) - 16,8\% pontos percentuais correspondentes à agropecuária e 56,5\% à produção mineral. Aos setores de comércio, indústria e serviços locais do sudeste paraense (setores $\beta$ a) coube $27 \%$ do VA local, representando16\% do total.

Os dois setores da produção rural, ademais, apresentam balanços de carbono bem diferentes: as fazendas, com $217,8 \mathrm{Gt}$ de $\mathrm{CO}_{2}$ equivalente, geram aproximadamente o triplo das emissões líquidas de 75,4 Gt de $\mathrm{CO}_{2}$ equivalente das unidades camponesas. Isso leva a custos de oportunidade social, medidos pela relação Valor Adicionado/Emissão líquida de $\mathrm{CO}_{2}$, bem diferentes entre as fazendas, de $\mathrm{R} \$ 2,95 / \mathrm{CO}_{2}$ equivalente, e os camponeses, de $\mathrm{R} \$ 6,69 / \mathrm{t} \mathrm{CO}_{2}$ equivalente. O mesmo verifica-se em relação aos custos de oportunidade privados - afetos aos proprietários - medidos pela relação Lucro (sem impostos)/Emissão líquida: $\mathrm{R} \$ 2,10 / \mathrm{t} \mathrm{CO}_{2}$ equivalente e $\mathrm{R} \$ 5,69 / \mathrm{t} \mathrm{CO}_{2}$ equivalente. 


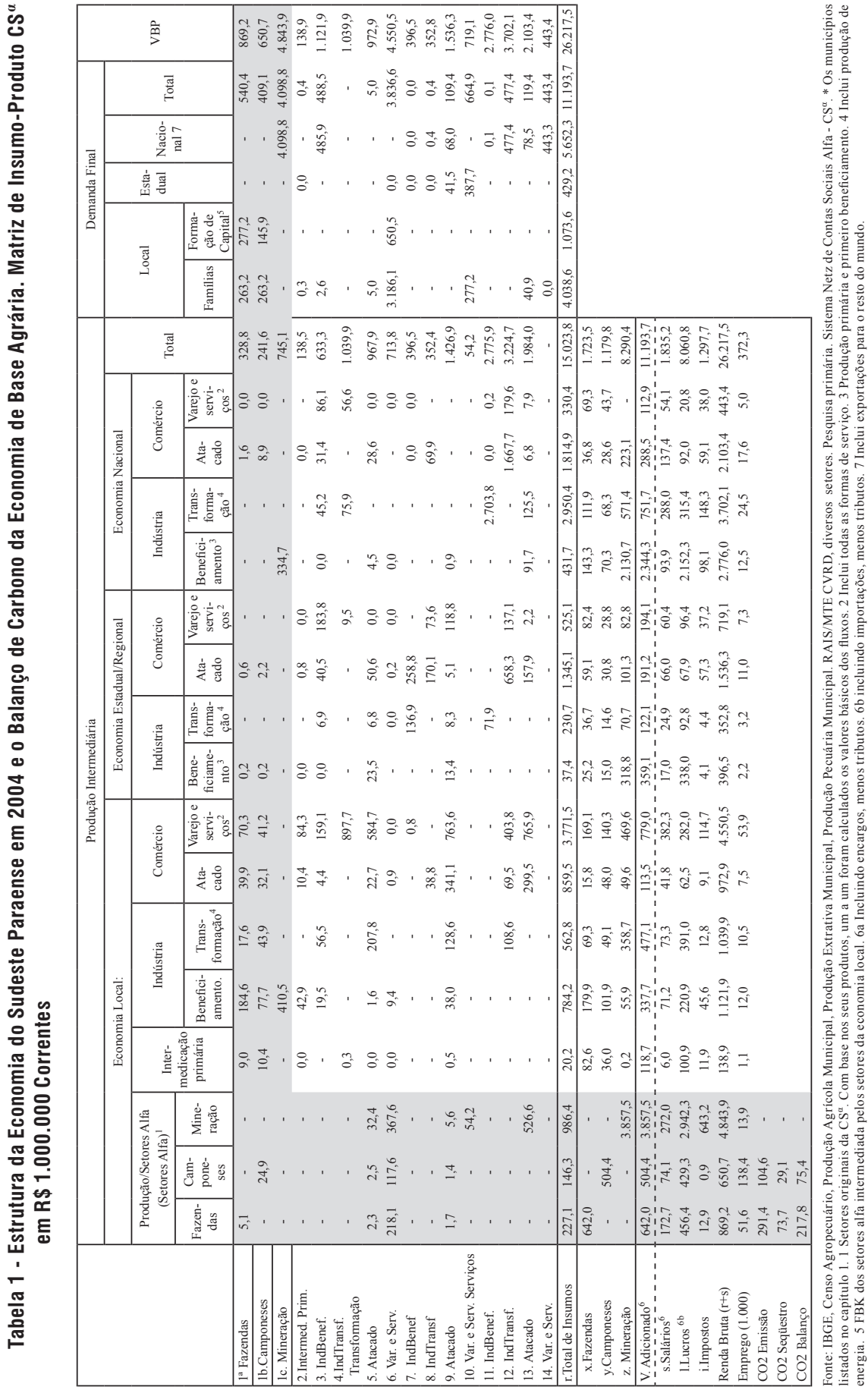




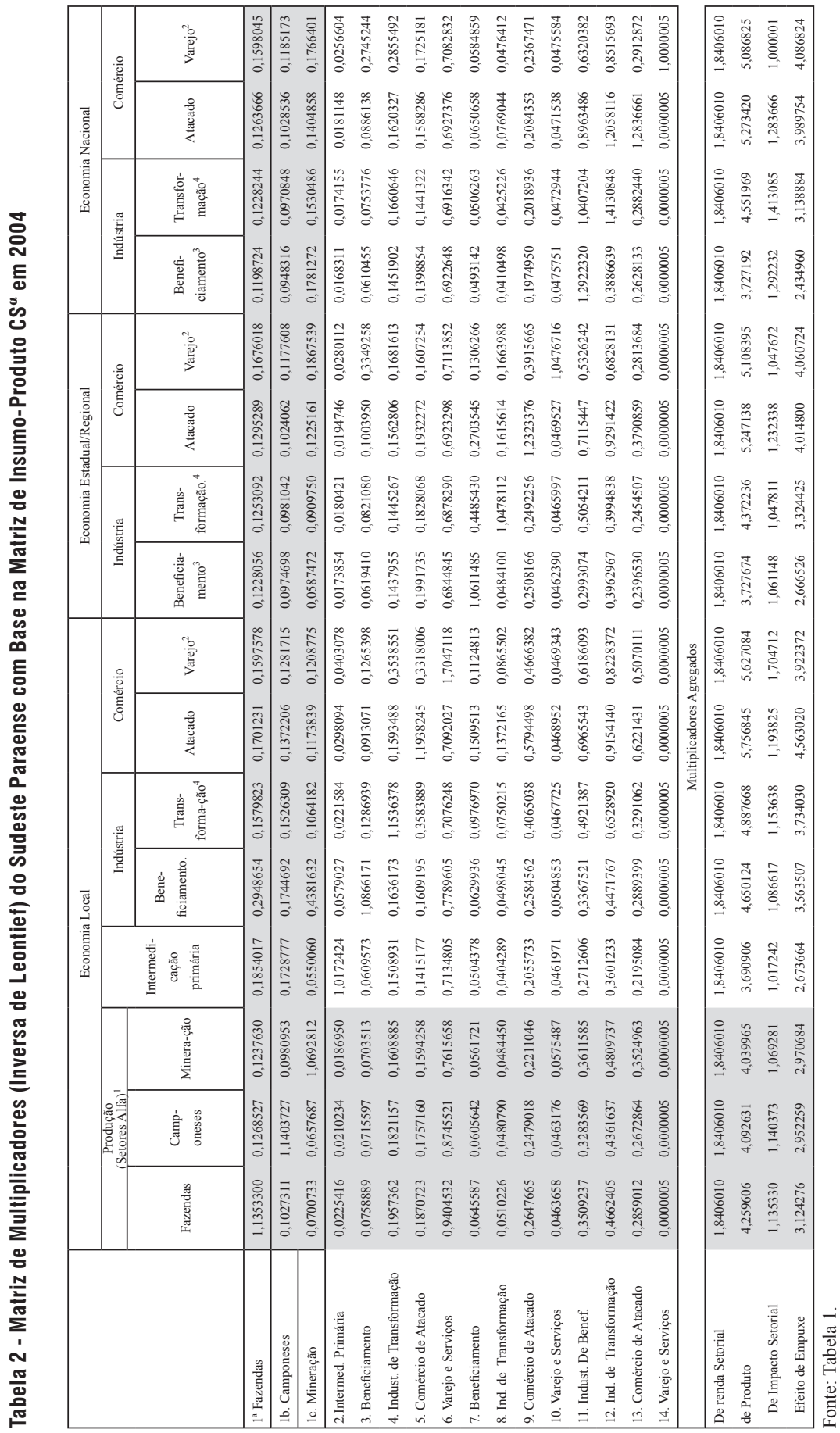




\section{B. Os Multiplicadores da Economia do Sudeste Paraense}

A matriz inversa de Leontief fornece os multiplicadores de renda e de produto de uma economia. Esses podem ser de dois tipos, dependendo de serem calculados considerando a renda e o consumo locais (o setor "famílias") como variáveis exógenas (tipo I) ou endógenas (tipo II). (Haddad, 1989: 317-318; Tosta et alii, 2004:252). Neste estudo trabalhamos apenas com os multiplicadores do Tipo II. Assim, foram calculados tendo o valor adicionado (renda das famílias) como sendo uma linha e o consumo final local como uma coluna a mais na matriz de coeficientes técnicos. Para a economia de base primária do Sudeste Paraense descrita na Tabela 1, calculamos os multiplicadores do Tipo II, considerando exógena toda a demanda final estadual e nacional - com a demanda final local, portanto, endógena. Os resultados estão na Tabela 2 onde, nas quatro últimas linhas encontram-se, também pela ordem, o multiplicador agregado de renda, os multiplicadores setoriais de produto e seus componentes, os multiplicadores de impacto setorial e os de efeito de empuxe.

\section{Os Multiplicadores - Impactos e Efeitos Setoriais}

O multiplicador agregado ou global de renda é $\mathrm{R} \$ 1,84$ : se se retira $\mathrm{R} \$ 1$ em produção do sistema econômico, ele reduzirá $\mathrm{R}$ \$ 1,84 e vice-versa no valor adicionado agregado. Injetando R 1 na demanda efetiva, o valor adicionado do sistema como um todo crescerá $\mathrm{R} \$ 1,84$. Os demais multiplicadores indicam como cada setor intermediará tais entradas e saídas de recursos no impacto sobre o valor da produção total e, por essa via, sobre as variáveis de renda, emprego e emissão de carbono de cada um deles. No que se refere ao setor alfa da produção rural camponesa, para cada unidade a mais ou menos na demanda final multiplica por 4,1 (1,1 de impacto setorial e 3 dos efeitos indiretos), e da produção rural patronal, por 4,3 (1,1 de impacto setorial e 3,2 de efeitos indiretos) na determinação da variação no valor da produção total.

\section{Variação nas Variáveis de Valor Adicionado, no Emprego e nas Variáveis do Balanço de Carbono como Resultado de Alterações no Valor Bruto da Produção}

Dispondo da matriz de multiplicadores é possível calcular as variáveis de valor adicionado e outras que se associam ao sistema, pelo mesmo raciocínio que permite a determinação do nível de atividade econômica em cada setor produtivo como uma função da demanda final efetiva. Assumida a hipótese de proporcionalidade entre qualquer 
dessas variáveis e o valor da produção em todos os setores da economia, pode-se estimar as variações respectivas, diretas, indiretas e induzidas, causadas pela expansão na demanda final de um determinado setor a partir da relação:

$$
U=\left(u_{j}\right)_{1 x n} \cdot(I-A)^{-1} . D F
$$

onde U é a variável em questão (o emprego total, por exemplo, ou a emissão de $\left.\mathrm{CO}_{2}\right)^{1} \mathrm{e}$ $\left(u_{j}\right)$ é o vetor linha $(1 x n)$ contendo os coeficientes respectivos de cada setor " $j$ ", obtidos pela divisão do valor real da variável no setor pelo seu valor da produção total; DF é o vetor coluna da variação na demanda efetiva.

\section{E. Política de Contenção, Mercado de Terras e Economia Local: Exercícios de Predição}

Utilizando a fórmula (1), podemos discutir a questão principal em que nos colocamos. Relembrando: dado que os esquemas de compensação para contenção do desmatamento implicam a entrada e saída de recursos, qual o resultado final desses fluxos sobre as variáveis fundamentais de renda e emprego, sobre suas relações com a base natural que a fundamenta e, portanto, sobre as próprias forças que produzem o desmatamento?

Tabela 3 - Diversas Condições de Compensação por Redução nas Emissões de Carbono no Sudeste Paraense como Variações na Demanda Final de 2004 (em R\$ milhões de 2005)

\begin{tabular}{|l|c|c|c|c|} 
& Exercício 1 & Exercício 2 & Exercício 3 & Exercício 4 \\
\hline $1^{\text {a} F a z e n d a s ~}$ & $-434,59^{1}$ & 0,00 & $-869,18^{4}$ & $-434,59^{1}$ \\
\cline { 1 - 3 } 1b.Camponeses & $-325,36^{1}$ & 0,00 & $869,18^{4}$ & $-325,36^{1}$ \\
\cline { 1 - 3 } 1c.Mineração & 0,00 & 0,00 & 0,00 & $6.563,05^{3}$ \\
\cline { 1 - 4 } 6.Varejo e Serviços & $442,88^{2}$ & $442,88^{2}$ & $442,88^{2}$ & $442,88^{2}$ \\
\hline
\end{tabular}

Fonte: Tabela 1. Notas: ${ }^{1} 50 \%$ do Valor Bruto da Produção das linhas correspondentes na Tabela $1 .{ }^{2} 50 \%$ do valor da linha "Lucros" nos setores alfa "Camponeses" e "Fazendas". ${ }^{3}$ Informação da CVRD (conf. Ceplan, 2006 ). ${ }^{4} 100 \%$ da produção das "Fazendas", maior poluidora, passa a ser feita nos moldes camponeses, cujo setor cresce na mesma proporção.

\footnotetext{
${ }^{1} \mathrm{Na}$ literatura especializada encontram-se outros métodos de calcular requerimentos e impactos físicos ambientais da produção a partir de matrizes Iinsumo-Produto. Particularmente interessantes e divulgados são os modelos desenvolvidos no Green Design Institute da Carnegie Mellon University, os quais combinam técnicas de insumo-produto e de análise de ciclo de vida na estimação endógena de impactos econômicos e ambientais - por matrizes de coeficientes técnicos, físicos, monetários e mistos operando nas transações intermediárias, ao invés de coeficientes em relação ao produto final, como fazemos, de modo que encontramos aí uma fonte de aprimoramento. Não obstante, tais modelos só recentemente vêm sofrendo ajustamento (por partição de matrizes nacionais) para análises regionais $-\mathrm{o}$ forte das nossas $\mathrm{CS}^{\alpha}$. Segundo Georgyi Cicas, cuja tese de doutorado é pioneira nos caminhos de regionalização da EIOLCA, "While both process LCA and EIO-LCA have been important decision making tools, neither of them have been able do perform regional and state level analysis accurately and efficiently" (2005:8).
} 
Quatro exercícios, cujos termos básicos se encontram na Tabela 3, ajudar-nos-ão a refletir sobre essa indagação. O primeiro procura retratar uma situação em que a política de compensação se faz em contexto idealizado, em que se cumprem contratos e não há pressões de mercado; o segundo discute o efeito do mercado de terras como mecanismo de pressão exógena; o terceiro reflete sobre pressões endógenas de demanda por produtos; o quarto aponta para outras perspectivas de política com vistas a interferir no balanço de carbono.

\section{F. Idealismo Tecnocrático}

$\mathrm{O}$ que ocorreria com a economia e com o balanço de $\mathrm{CO}_{2}$ se um programa de compensação por redução de emissão lograsse reduzir em 5 anos $50 \%$ da produção que fundamentava o balanço de carbono verificado em 2004, por justa compensação aos proprietários dos estabelecimentos rurais no nível verificado de seus ganhos? Para isso, o esquema de compensação remuneraria os gestores da produção rural em 50\% dos seus lucros anuais: por valores, pois, equivalentes ao custo de oportunidade dos recursos de capital por eles aplicados àquela produção. Na hipótese de que esses agentes continuarão no mesmo lugar, ${ }^{2}$ o movimento precedente resultaria numa entrada de $\mathrm{R} \$ 442,88$ milhões por ano na economia local por compras de bens e serviços pelos que receberam a compensação em troca da redução em $50 \%$ das respectivas produções. Nisso, têm-se introjetada em contexto sistêmico a remuneração dos agentes responsáveis diretos pela produção, antes do estabelecimento dos contratos de não emissão.

Nesse primeiro exercício, tais contratos são cumpridos e não há substituição da produção renunciada - o que se expressa, no modelo, na redução da oferta efetiva em montantes correspondentes avaliados em $\mathrm{R} \$ 434,59$ e $\mathrm{R} \$ 325,36$ correspondentes a 50\% do valor da produção dos setores alfa camponês e patronal, respectivamente. As variações absolutas resultantes dessa operação encontram-se na Tabela 4, enquanto as variações relativas em relação a 2004, na primeira parte do Gráfico 1: lograr-se-ia reduzir as emissões em $-53,8 \%, 3,8$ pontos percentuais a mais que o projetado. Isto, contudo, ao custo de uma considerável redução da economia local (apesar da manutenção do mesmo nível de produção do setor alfa mineral), cujo valor adicionado reduziria em termos absolutos de -R \$ 601,33 milhões: uma redução de $-8,8 \%$, em relação a 2004; a massa de salários cairia $-11,6 \%$, os lucros $-9,6 \%$, os impostos $-0,6 \%$ e o emprego nada menos que $-35,6 \%$. Haveria um reordenamento na composição da renda em favor das economias estadual e nacional, uma vez que nesses níveis todas as variáveis expandiriam, não obstante a baixas taxas.

\footnotetext{
${ }^{2}$ A outra hipótese, a de que os agentes que recebem as compensações mudam para lugares mais amenos, poderá ser explorada em outro momento.
} 


\section{G. O Mercado de Terras como Mecanismo de Pressão Exógena}

O exercício anterior corresponde a uma perspectiva presente no debate em andamento sobre compensações para evitar desmatamento e emissão de $\mathrm{CO}_{2}$. Argumenta-se que dada a "falha de estado" em coibir os "passivos ambientais" por incapacidade técnica de fazer valer as restrições formais, tudo dependeria de decisões privadas e da compensação aos "bons empresários" por não derrubarem suas matas, de acordo com seu custo de oportunidade. Dada, agora, a "falha de mercado" que não atribui valor "aos serviços ambientais da floresta" como sink de carbono, por exemplo, ao estado competiria cobrir o ônus da compensação. Nisso consistiria um "pacto redentor" (Young, 2007; Nepstad, 2008; Veiga, 2007).

Esse raciocínio tem pressupostos que carecem explicitação:

1) por se organizar em torno da ideia de custo de oportunidade privado, refere-se a um objeto de contrato ("serviço ambiental" produzido por mata originária) que já (e só) existe na condição de coisa apropriada;

2) essa condição, por sua vez, refere-se à propriedade ou posse da terra - nesse sentido, o fundamento do objeto último dos contratos a estabelecer não é a "floresta originária" e o que representa objetivamente (bioma, ecossistema), como ativo especifico face aos seus atributos; mas sim um ativo genérico "terra".

Ocorre que, como ativo genérico, "terra" é produto de ampla circulação, posto que resulta de processo de produção acoplado a um mercado: o mercado de terras. Como todo processo de produção em economia de mercado, a produção de terras se faz continuadamente enquanto existirem o poder de compra demandando seus resultados e os pressupostos da produção - engenho humano adequado à transformação e a matériaprima a ser transformada.

Tabela 4 - Variações nas Variáveis-Chave da Economia do Sudeste Paraense Produzidas por Operações de Compensação por Redução de Emissão de $\mathrm{CO}_{2}$

\begin{tabular}{|c|c|c|c|c|c|c|c|c|}
\hline \multirow[b]{2}{*}{ Nível } & \multicolumn{5}{|c|}{ Variáveis da Economia (em R\$ milhões de 2005) } & \multicolumn{3}{|c|}{ Balanço de $\mathrm{CO} 2\left(10^{6}\right)$} \\
\hline & $\begin{array}{c}\text { Valor } \\
\text { Adicionado }\end{array}$ & Salários & Lucros & Emprego & Impostos & Emissão & Seqüestro & $\begin{array}{l}\text { Balanço } \\
\text { Líquido }\end{array}$ \\
\hline \multicolumn{9}{|c|}{ Exercício 1 (Variação Absoluta) } \\
\hline Local & $-601,33$ & $-126,54$ & $-469,53$ & $-102,96$ & $-5,26$ & $-213,22$ & $-55,37$ & $-157,84$ \\
\hline Estadual & $-0,5$ & $-0,62$ & 0,43 & $-0,05$ & $-0,31$ & 0 & 0 & 0 \\
\hline Nacional & 18,22 & 2,91 & 13,62 & 0,31 & 1,69 & 0 & 0 & 0 \\
\hline \multicolumn{9}{|c|}{ Exercício 2 (Variação Absoluta) } \\
\hline Local & 389,29 & 108,65 & 246,27 & 28,83 & 34,38 & 32,84 & 8,54 & 24,31 \\
\hline Estadual & 89,72 & 15,47 & 64,48 & 2,32 & 9,77 & 0 & 0 & 0 \\
\hline Nacional & 336,15 & 52,29 & 253,27 & 5,52 & 30,59 & 0 & 0 & 0 \\
\hline
\end{tabular}




\begin{tabular}{|c|c|c|c|c|c|c|c|c|}
\hline \multicolumn{9}{|c|}{ Exercício 3 (Variação Absoluta) } \\
\hline Local & 419,25 & 30,62 & 368,44 & 167,65 & 20,2 & $-116,15$ & $-25,41$ & $-90,74$ \\
\hline Estadual & 83,85 & 14,5 & 60,19 & 2,17 & 9,16 & 0 & 0 & 0 \\
\hline Nacional & 312,06 & 48,53 & 235,13 & 5,13 & 28,4 & 0 & 0 & 0 \\
\hline \multicolumn{9}{|c|}{ Exercício 4 (Variação Absoluta) } \\
\hline Local & $7.792,24$ & $1.076,23$ & $5.598,43$ & 186,26 & $1.117,58$ & 162,57 & 42,27 & 120,3 \\
\hline Estadual & 725,98 & 131,71 & 513,17 & 19,11 & 81,11 & 0 & 0 & 0 \\
\hline Nacional & $2.978,13$ & 479,8 & $2.221,38$ & 51,22 & 276,95 & 0 & 0 & 0 \\
\hline \multicolumn{9}{|c|}{ Valores em 2004} \\
\hline Local & $6.829,83$ & $1.093,46$ & $4.885,26$ & 288,96 & 851,12 & 395,99 & 102,78 & 293,21 \\
\hline Estadual & 866,47 & 168,32 & 595,16 & 23,69 & 102,99 & - & - & - \\
\hline Nacional & $3.497,40$ & 573,42 & $2.580,40$ & 59,60 & 343,57 & - & - & - \\
\hline
\end{tabular}

Fonte: Elaboração do autor.

Tal mercado se configura em institucionalidade própria (Polanyi, 1992), expressandose concretamente nos preços e na "natureza" do que movimenta. Pesquisa anual do Instituto iFNP, que abrange o período 2001 a 2007 em 241 municípios da Amazônia (nos estados do Acre, Amapá, Amazonas e Pará), expõe, após algum processamento, as três grandes categorias empíricas da mercadoria terra: "terras com mata", "terras para pasto" e "terras para lavoura". O Gráfico 2 apresenta, na parte (A), as respectivas evoluções dos preços no período em valores corrigidos para R \$ de 2007, na parte (B), as relações entre eles. Os seguintes pontos se destacam:

Os preços de "terras com mata" são parcelas dos demais, em média $43 \%$ dos das "terras para pasto" e $23 \%$ dos das "terras de lavouras". O mercado de terras informa, assim, só reconhecer os preços das "terras com mata" como parcelas na formação dos preços das pastagens e terras agrícolas. Isso pressupõe uma regulação que, em última instância, transforma "florestas originárias" (não mercadoria) em "terras com mata" (mercadoria) a preço sistemicamente controlado de modo a não comprometer, no passo seguinte, a viabilidade da transformação dessas em "terras de pastagem" ou "terras para lavoura". De outra perspectiva, o mercado de terras pressupõe um processo de produção de "terras com mata", a partir de "matas originárias" (estas as matérias-primas daquelas), que estabelece um "preço de produção" das primeiras compatível com a rentabilidade das estruturas produtivas que têm como insumos "terras de pastagem" ou "terras para lavoura". O poder de compra desses demandantes garante e define toda a cadeia.

Os poucos dados até agora divulgados do último Censo Agropecuário permitem averiguar os elementos substantivos desse mercado: seus fluxos reais expressos nas quantidades em jogo. Tomando os estoques totais de terras nos estabelecimentos da Região Norte, entre os censos de 1995 e 2006 ocorreu uma variação de 14,2 milhões de hectares (Tabela 5). Observando a distribuição dessa diferença pelos diferentes tipos de aplicação, é possível estabelecer que nos 11 anos em questão, os operadores dos estabelecimentos adquiriram 5,4 milhões de hectares de "terras para lavoura", 8,2 milhões 
de "terras de pastagem" e, ademais, adicionaram 0,5 milhão de hectares às reservas de "terras com mata".

Esses "produtos" (os dois primeiros itens constituindo parcelas da formação bruta de capital fixo do setor, com tempo de depreciação variável; o último, uma reserva de contingência) não existiam, na região em 1995, tendo sido, portanto, produzidos ao longo do período em tela, por mecanismos de transformação da matéria-prima "floresta originária".

\section{Gráfico 1 - Quatro Exercícios de Impacto de Esquemas de Compensação para Redução da Emissão Líquida de $\mathrm{CO}_{2}$ na Economia do Sudeste Paraense}

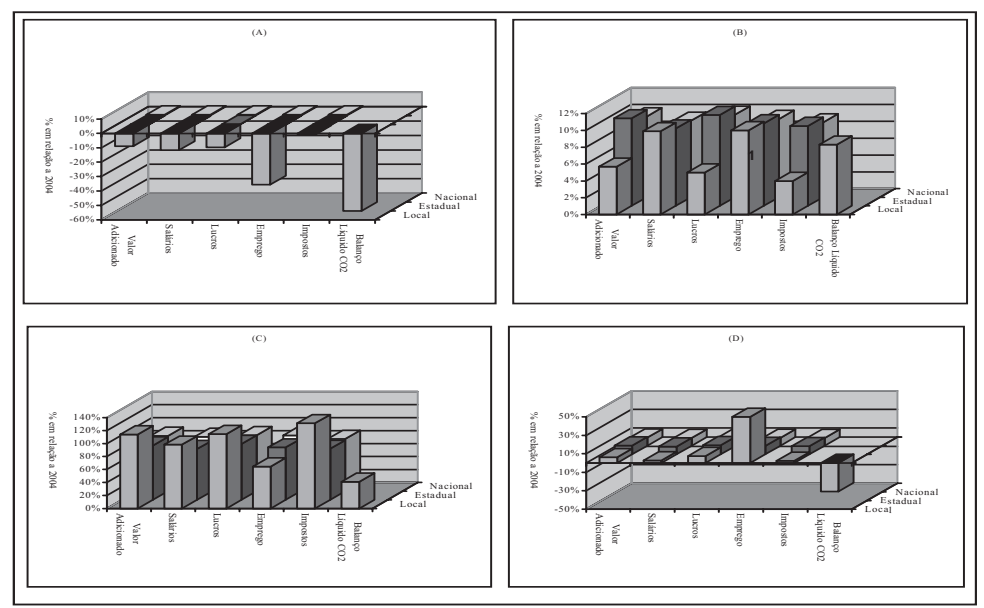

Fonte: Tabela 4.

Abstraindo as formas de produção e os custos correspondentes de transformação da "floresta originária" em "terras com mata", de difícil aferição, a avaliação monetária desse mercado exige a quantificação de um movimento "primário" de vendas das "terras com mata" e de um movimento "derivado" de venda de "terras para pastagem" e "terras para lavoura". Considerando as médias dos preços (corrigidos para 2007) por tipo de "terra" como válidas para todo o período, no primeiro movimento foram despendidos $\mathrm{R} \$ 3,4$ bilhões e, no segundo, R $\$ 11,6$ bilhões, perfazendo o total de vendas diretas algo em torno de R $\$ 15$ bilhões de reais em 11 anos - aproximadamente um VBP de R\$1,4 bilhões, possibilitando Valor Adicionado de R\$ 1,0 bilhão por ano.

Suponhamos que em 1995 tivesse existido uma política para toda a Região Norte de contenção do desmatamento à base de remuneração dos proprietários de "reservas de 
mata" a um justo preço - ao custo de oportunidade -, tal como propusemos na sessão anterior. Na verdade, esses proprietários seriam os únicos atores presentes, detentores do único objeto de contração que essa perspectiva de política pode considerar. Consideremos que em esforço máximo da sociedade tivessem sido feitos contratos cobrindo todos os 25,7 milhões de hectares (pois o propósito teria sido, digamos, o de "desmatamento zero"), a um preço determinado pela atividade de menor rendimento, a pecuária extensiva - digamos, a $\mathrm{R} \$ 40,00 \mathrm{p} / \mathrm{ha}$.

A política custaria em torno de $\mathrm{R} \$ 1,0$ bilhão de reais a cada ano (aproximadamente a disponibilidade média real do FNO, nesse período). Em 2006 teríamos nada muito diferente do balanço real apresentado na Tabela 5. A política teria sido eficiente, posto que as reservas contratadas estariam intactas, até acrescidas, para regozijo dos policy makers, que provavelmente também estariam felizes porque os "bons empresários" teriam cumprido seus contratos. Mas, ao lado disso, teríamos os mesmo 11,6 milhões de hectares adicionalmente transformados que nos apresenta a realidade do Censo. Com uma diferença, entretanto: a sociedade teria despendido $\mathrm{R} \$ 11,0$ bilhões de reais literalmente para nada - ou melhor, para acréscimo do patrimônio dos proprietários com reserva de "terras com mata", tanto mais quanto mais as possuíssem.

Gráfico 2- Mercado de Terras na Região Norte: Evolução(A) e Relação dos Preços (B) de "Terra com Mata", "Terra para Pasto" e "Terra para Lavoura", 2001 a 2007 (Preços em R\$ Corrigidos para 2007)

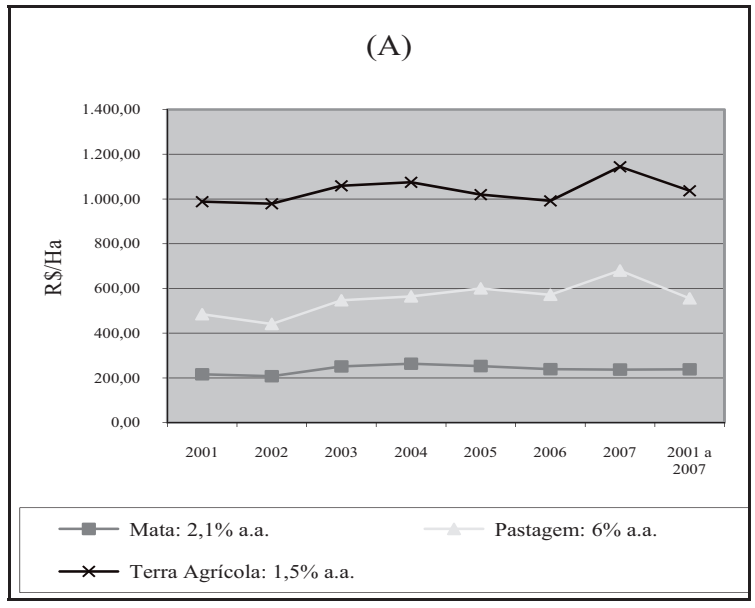




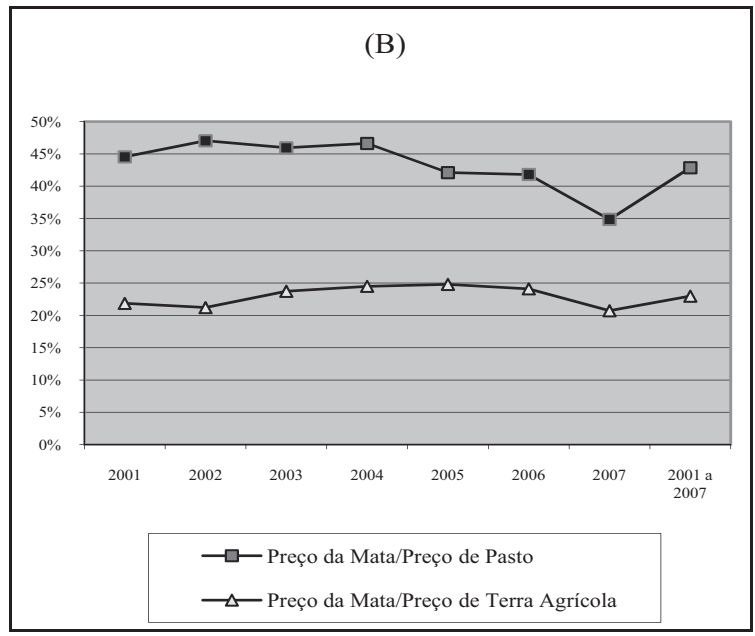

Fonte: iFNP, Anualpec 2003, 2004, 2005, 2006, 2007 e 2008. Processamento do autor.

\section{Notas Metodológicas:}

1 - O Instituto iFNP publica desde 2003 preços de terras tipificando-as "com mata", "pastagens" e "terras agrícolas" a partir de pesquisa de campo que cobrem 22 municípios doAcre, 16 municípios do Amapá, 64 do Amazonas e 139 do Pará.

2 - Médias aritméticas simples dos preços corrigidos pelo IGP-DI para 2007 de acordo com tipo de terras.

3 - Taxas calculadas por regressão das transformações logarítmicas em relação ao tempo.

Para a economia do sudeste paraense o mercado de terras foi modelado pelas $\mathrm{CS}^{\alpha}$, considerando os preços dos três tipos de terras vigentes em 2004 nos municípios da mesorregião incluídos na pesquisa da iFNP, e pressupondo que as necessidades de terras para explicar a expansão das atividades foram determinadas pelos parâmetros tecnológicos vigentes em 1995 e atendidas necessariamente através do mercado - o que garantiu a preservação das reservas de "terras com mata" dos estabelecimentos em 1995. Os resultados foram internalizados na economia do sudeste paraense apresentada na Tabela 1, já comentados, e permitiram, ademais, estruturar agregados para a mesorregião num balanço semelhante ao da Tabela 5, só que cobrindo o período de 1995 a 2004 (ver Tabela 6). 
Tabela 5 - Mercado de Terras na Região Norte entre 1995 e 2006

\begin{tabular}{|c|c|c|c|c|c|}
\hline & & \multicolumn{2}{|c|}{$\begin{array}{c}\text { Estoque de Terras } \\
\text { nos Estabelecimentos: }\end{array}$} & \multicolumn{2}{|c|}{$\begin{array}{l}\text { Passagem das "Terras com Mata" para a } \\
\text { Condição de Capital Físico:"Terra de Pastagem", } \\
\text { "Terras para Lavoura" e "Reserva de Mata" }\end{array}$} \\
\hline & & $\begin{array}{l}1995 \\
(\mathrm{~A})\end{array}$ & $\begin{array}{l}2006 \\
(\mathrm{~B})\end{array}$ & $\begin{array}{l}\text { Fluxo Real (Há) } \\
(\mathrm{B})-(\mathrm{A})=(\mathrm{C})\end{array}$ & $\begin{array}{l}\text { Fluxo Monetário (R\$) } \\
\text { (C)*Preço Médio }\end{array}$ \\
\hline \multicolumn{2}{|c|}{ Terras para Lavoura } & 1.972 .056 & 7.406 .786 & 5.434 .730 & 3.020 .839 .633 \\
\hline \multicolumn{2}{|c|}{ Terras de Pastagens } & 24.386 .621 & 32.630 .532 & 8.243 .911 & 8.546 .530 .707 \\
\hline \multicolumn{2}{|c|}{ Reserva de Terras com Matas } & 25.756 .634 & 26.283 .121 & 526.487 & \\
\hline \multicolumn{2}{|c|}{ Total de Terras Apropriadas } & 52.115 .311 & 66320439 & 14.205 .128 & 11.567 .370 .340 \\
\hline \multirow{2}{*}{$\begin{array}{l}\text { Transformação Necessária } \\
\text { de "Floresta Originária" em } \\
\text { "Terra com Mata" }\end{array}$} & $\begin{array}{l}\text { Fluxo Real } \\
\quad(\mathrm{Ha})\end{array}$ & & & $\begin{array}{c}14.205 .128 \\
(1.291 .375 / \mathrm{ano})\end{array}$ & \\
\hline & $\begin{array}{l}\text { Fluxo } \\
\text { Monetário } \\
(\mathrm{R} \$)\end{array}$ & & & & $\begin{array}{c}3.384 .818 .012 \\
(307.710 .728 / \mathrm{Ano})\end{array}$ \\
\hline \multicolumn{2}{|c|}{$\begin{array}{l}\text { Valor Total Movimentado } \\
\text { no Mercado de Terras (R\$) }\end{array}$} & & & & $\begin{array}{c}14.952 .188 .352 \\
(1.359 .289 .850 / \text { Ano })\end{array}$ \\
\hline
\end{tabular}

Fonte: IBGE, Censo de 1995 e Censo de 2006.

\section{Tabela 6 - Estimativa do Mercado de Terras no Sudeste Paraense entre 1995 e 2004}

\begin{tabular}{|c|c|c|c|c|c|}
\hline & & \multicolumn{2}{|c|}{$\begin{array}{c}\text { Estoque de Terras } \\
\text { nos Estabelecimentos: }\end{array}$} & \multicolumn{2}{|c|}{$\begin{array}{l}\text { Passagem das "Terras com Mata" para } \\
\text { a Condição de Capital Físico: "Terra } \\
\text { de Pastagem", "Terras para Lavoura" e } \\
\text { "Reserva de Mata" }\end{array}$} \\
\hline & & $\begin{array}{l}1995 \\
(\mathrm{~A}) \\
\end{array}$ & $\begin{array}{c}2004 \\
(\mathrm{~B})\end{array}$ & $\begin{array}{l}\text { Fluxo Real } \\
\text { (Há) } \\
(\mathrm{B})-(\mathrm{A})=(\mathrm{C})\end{array}$ & $\begin{array}{l}\text { Fluxo Monetário } \\
\text { (R\$) } \\
\text { (C)*Preco Médio }\end{array}$ \\
\hline \multicolumn{2}{|c|}{ Terras para Lavoura } & 347.082 & 446.260 & 99.178 & 151.206 .899 .7 \\
\hline \multicolumn{2}{|c|}{ Terras de Pastagens } & 4.829 .473 & 6.490 .670 & 1.661 .198 & 1522398.4722 \\
\hline \multicolumn{2}{|c|}{$\begin{array}{l}\text { Reserva de Terras } \\
\text { com Matas }\end{array}$} & 4.992 .744 & 4.992 .744 & 0 & \\
\hline \multicolumn{2}{|c|}{ Total de Terras Apropriadas } & 10.169 .298 & 11.929 .674 & 1.760 .376 & 1.673 .605 .372 .0 \\
\hline \multirow{2}{*}{$\begin{array}{l}\text { Transformação Necessária } \\
\text { de "Floresta Originária"em } \\
\text { "Terra com Mata" }\end{array}$} & $\begin{array}{l}\text { Fluxo Real } \\
(\mathrm{Ha})\end{array}$ & & $\begin{array}{c}1.760 .376 \\
(195.597,30 / \text { ano })\end{array}$ & & \\
\hline & $\begin{array}{c}\text { Fluxo } \\
\text { Monetário } \\
\text { (R\$) }\end{array}$ & & & $\begin{array}{c}638.133 .132,0 \\
(70.903 .681,3 / \\
\text { Ano }) \\
\end{array}$ & $\begin{array}{c}3.384 .818 .012,0 \\
(307.710 .728 / \text { Ano })\end{array}$ \\
\hline \multicolumn{2}{|c|}{$\begin{array}{l}\text { Valor Total Movimentado } \\
\text { no Mercado de Terras (R\$) }\end{array}$} & & & & $\begin{array}{c}2.311 .738 .504,0 \\
(256.859 .833,8 / \mathrm{Ano})\end{array}$ \\
\hline
\end{tabular}

Fonte: IBGE, Censo de 1995 e 2004. Estimativas das $\mathrm{CS}^{\alpha}$.

Ao lado da manutenção dos 5 milhões de hectares das reservas de "terras com matas", o mercado de terras na mesorregião teria produzido, entre 1995 e 2004, 1,7 milhões de novas "terras para pastagem" (o Censo informa 1,6 milhões até 2006) e 99,2 mil hectares de novas "terras para lavoura" a partir da conversão de um total de 1,8 milhões de hectares de "floresta originária" em "terras com mata". O fluxo primário médio de R\$ 256,9 milhões por ano expressou-se, no ano de 2004, em R \$ 465,4 milhões de VBP e R\$ 185,3 milhões de VA, já acima comentados. 
Esta é a história. Conhecendo-a, parece prudente prospectar o futuro, considerando uma situação na qual o programa de compensação por redução de emissão sob escrutínio lograsse reduzir $50 \%$ da produção que fundamentava o balanço de carbono verificado em 2004, compensando produtores estabelecidos no nível verificado de seus ganhos, mas, ao mesmo tempo, novos produtores venham a se estabelecer, mediados pelo mercado de terras, para o qual carrearam poder de compra exógeno, repondo a produção dos setores alfa rurais no nível de 2004. Concretamente, o esquema de compensação remuneraria os agentes gestores da produção rural em $50 \%$ dos lucros anuais, o que implicaria uma entrada de $\mathrm{R} \$ 442,88$ milhões por ano na economia local por compras de bens e serviços e não há redução na produção. O resultado dessa situação encontrase na segunda parte da Tabela 4 e na seção (B) do Gráfico 2: as variáveis da economia local cresceriam todas, o valor adicionado expandiria, em termos absolutos, R \$ 419,2 milhões $(5,7 \%)$ em relação a 2004; os salários e o emprego cresceriam, respectivamente, $9,9 \%$ e $10,0 \%$, os lucros $5 \%$ e os impostos $4 \%$, gerando como consequência uma expansão das emissões líquidas de carbono de $8,3 \%$. A economia estadual expandiria o valor adicionado em $\mathrm{R} \$ 89,72$ milhões (10,4\% em relação a 2004) e a nacional em $\mathrm{R} \$ 341,56$ milhões $(9,6 \%)$. O fracasso da política de contenção corresponderia, nesse caso, a um notável sucesso econômico.

\section{G. O Mercado Local de Produtos e os Mecanismos Endógenos de Pressão}

Como já demonstrado, o sudeste paraense constitui economia complexa, com setores não rurais de grande capacidade expansiva. Importa indagar, pois, o que ocorreria com a economia e com o balanço de $\mathrm{CO}_{2}$ se um programa de compensação por redução de emissão lograsse reduzir em 5 anos $50 \%$ da produção que fundamentava o balanço de carbono verificado em 2004 por justa compensação aos proprietários dos estabelecimentos rurais no nível verificado de seus ganhos. Nesse caso, porém, a produção primária não agrícola se expandiria fortemente. Isto significa que um esquema de compensação, exatamente como na primeira situação, remunera os agentes gestores da produção rural em $50 \%$ dos lucros anuais.

$\mathrm{Na}$ hipótese de que esses agentes continuarão no mesmo lugar, haveria uma entrada de R $\$ 442,88$ milhões por ano na economia local por compras de bens e serviços, em troca da redução em $50 \%$ das respectivas produções - expressas na redução da demanda efetiva dos valores de $\mathrm{R} \$ 434,59$ e $\mathrm{R} \$ 325,36$ milhões dos setores alfa camponês e patronal, respectivamente. Porém, como é o caso da economia estudada, a mineração mais que dobra sua produção anual, acrescendo aproximadamente R \$ 6,6 bilhões, como vem sendo nos planos e na realidade da Companhia Vale do Rio Doce nos próximos anos (conf. Costa, 2008c). O resultado dessa operação seria uma explosão nas variáveis 
econômicas nos montantes absolutos observados na última seção da Tabela 4 e relativos na parte $(\mathrm{C})$ do Gráfico 3. Todas as variáveis da economia local cresceriam, bem como o valor adicionado e a massa de lucros na liderança, cabendo obviamente a maior parte ao setor mineral. Não obstante, o emprego cresce $64,5 \%$ e a massa de salários $98,4 \%$, produzindo um impulso independente nos setores rurais e urbanos da economia local que faz as emissões líquidas de carbono crescer em 41\% em relação a 2004, apesar da redução obtida. Expansão importante verificar-se-ia, também, na economia estadual e nacional. A dinâmica da economia local autônoma tornou a política de contenção, nesse caso, inócua.

\section{H. Mudanças Tecnológicas e Capacidade Institucional Outras Possibilidades de Política}

Um exercício adicional deve ser ponderado, por fim, considerando a seguinte questão: $\mathrm{O}$ que ocorre com a economia e com o balanço de $\mathrm{CO}_{2}$ se um programa de redução de emissão lograr induzir a conversão da base produtiva dos sistemas que emitem mais, para os sistemas que emitem menos, de modo que em 5 anos toda produção seria feita com base nos sistemas que em 2004 mostraram-se menos emissores? Recursos de R\$ 442,88 milhões por ano fluirão na economia, em parte aplicados em conhecimentos (C\&T), bônus e subsídio de crédito como forma de remuneração de serviços ambientais produzidos pelos sistemas produtivos em operação, inclusive e principalmente os baseados no "bioma". Em parte, esses recursos fluirão também como resultados de ações do estado para coibir a transformação das "florestas originárias", que só existem na condição de ativo público, em "terras com mata", atacando o principal mecanismo do mercado de terras - a "grilagem" (Benatti, 2008; Costa, 2008). Os resultados dessa operação podem ser avaliados na quarta parte da Tabela 4 e na parte (D) do Gráfico 1: Todas as variáveis da economia local cresceriam, o valor adicionado $6,1 \%$ e a massa de salários $2,8 \%$, a massa de lucros $7,5 \%$. Isso ao lado da redução da emissão líquida de $\mathrm{CO}_{2}$ em $31 \%$. Neste caso se teria uma situação win-win: uma política de conversão tecnológica logra reduzir as emissões, ao mesmo tempo que produz dinâmica.

\section{Conclusões}

Tratando uma economia local real, sua configuração macro e suas relações com os sistemas envolventes da economia estadual e nacional, algumas questões sobre a aplicação futura de esquema de compensação podem ser discutidas mais acuradamente. Os exercícios efetuados permitem indicar o seguinte: 
1. No que se refere às emissões, há diferenças importantes entre os custos de oportunidade social (refere-se, na matriz $\mathrm{CS}^{\alpha}$ da Tabela 1, ao total do Valor Adicionado dividido pelo Balanço Líquido de $\mathrm{CO}_{2}$ ) dos estabelecimentos patronais, de $\mathrm{R} \$ 2,95 / \mathrm{t} \mathrm{CO}_{2}$ equivalente, e dos camponeses, de $\mathrm{R} \$ 6,69 / \mathrm{t} \mathrm{O}_{2}$ equivalente;

2. Há diferenças importantes, também, entre os custos de oportunidade privados (Lucros divididos por Balanço Líquido de $\mathrm{CO}_{2}$ ) dos estabelecimentos patronais, de $\mathrm{R} \$ 2,09 / \mathrm{CO}_{2}$ equivalente, e dos camponeses, de $\mathrm{R} \$ 5,69 / \mathrm{t} \mathrm{CO}_{2}$ equivalente;

3. Os impactos e efeitos derivados de ações exógenas, como os associados a um esquema de evitação de desmatamento e redução de emissão de carbono, têm medidas precisas e não são triviais: o multiplicador agregado de renda da economia do Sudeste Paraense é 1,84; o multiplicador setorial de produto da produção rural camponesa, 4,26; da produção patronal, 4,1;

4. Por conta das mediações sistêmicas que se expressam nesses parâmetros, esquemas de compensação centrados exclusivamente nos agentes e focados em redução da produção produzirão perdas sistemáticas para economia local:

a. Porque se compensa, mesmo quando num acordo justo e de valores equivalentes, apenas parte do valor adicionado perdido pela renúncia à produção;

b. Porque maior número de concatenações é ativado em torno da produção primária que deixa de existir (indústria de beneficiamento, indústria de transformação, comércio) do que em torno das mercadorias que entram acabadas (comércio), levando a um diferencial sistemicamente perdido.

Em tal contexto, formam-se tensões proporcionais às perdas. Desemprego, redução da taxa de lucro, redução da massa de impostos se fazem sentir e solapam adesões;

5. Esquemas de compensação para evitar a expansão da produção formam tensões endógenas para que se amplie a produção. Aqui, também, por duas razões:

a. Porque se forma renda sem produção e

b. Porque, mediada pelos multiplicadores, essa renda se amplia criando demanda adicional.

A resolução dessas tensões, cuja força resultante variará com a complexidade da economia, pode resultar em efetiva expansão da produção, sem a quebra dos contratos estabelecidos com os agentes com vistas à contenção do desmatamento. Isso porque outros agentes podem se apresentar para resolver os desequilíbrios elevando a oferta de bens pelos mesmos métodos da produção anterior, sem que possam ser interpelados pelos mecanismos de enforcement do esquema de compensação. Isso poderia criar, nas 
economias locais, dois tipos de agentes derivados dos esquemas de compensação: um, rentista, que não desmata em sua propriedade, e um, produtivo, que desmata para fornecer o que o rentista precisa e não mais produz. O objetivo almejado, nesse contexto, pode ser totalmente frustrado;

6. Em casos como o do sudeste paraense, em que a economia tem outras bases cuja dinâmica amplia a massa de salário e cria concatenações internas por expansão da demanda intermediária, as tensões discutidas no item anterior se ampliam na razão do dinamismo - é dizer, diretamente proporcional à sua força de polarização. Nesses casos, é difícil supor sucesso em uma política centrada em agentes e visando unicamente a contenção pela não produção. Um amplo programa centrado na elevação da capacidade produtiva em bases tecnológicas de baixo balanço líquido de emissão de carbono se torna absolutamente necessário - a chave de novas possibilidades;

7. Esquemas de redução de emissão por alteração na forma de produzir - que favoreçam os sistemas já existentes com balanços de carbono defensáveis, em detrimento dos que apresentam maior emissão líquida - parecem constituir base para estratégias win-win: mediante as quais se reduzirá emissão líquida ao lado de expansão da economia;

8. Por outro lado, tensões exógenas - como preços tendencialmente crescentes de carne e grãos no mercado externo e brasileiro, não obstante a presente crise - materializam-se na forma de poder de compra demandando "terras" que só existem como suporte de "florestas originárias". A produção de terras que a partir daí tem lugar, o principal processo por trás dos desmatamentos, é autônoma, e por se basear em métodos que se situam à margem da institucionalidade formal, está fora do alcance de qualquer esquema de "evitação" orientada à compensação, pelo Estado, de agentes privados, tornando-se no mecanismo principal de leaking do conjunto de atividades que se pretende evitar. É imprescindível, assim, o esforço de contenção do mercado de terras em dois momentos: quando da transformação do ativo específico "floresta primária" em "terras com mata" e no momento da legitimação do produto final - "terras para pasto" e "terras para lavoura" (Costa, 2009c).

a. No primeiro momento, são exigidas as capacidades formal e técnica do Estado para proteger os ativos públicos, em particular o bioma, ativo específico e distintivo da região e do país;

b. No segundo, as formas de titularidade deverão distinguir entre direito fundiário, relativo estritamente ao ativo "terra", e o direito aos "ativos ambientais originários". Ao não se reduzir o último ao primeiro, ao ente público se reservará, sempre, o poder de questionar o agente privado quanto ao seu uso e alienação.

No conjunto, esses resultados nos indicam as dificuldades de uma política de contenção das emissões tratando: a) apenas um lado da dialética produção agrícola x manutenção da floresta e b) apenas uma dimensão do sistema econômico. Pagar aos agentes que controlam floresta para que renunciem a produzir não elimina as necessidades que 
forçam a existência dessa produção. Estabelecidas, tais necessidades criam os agentes que as correspondem.

Isso nos coloca a necessidade de pensar políticas de contenção de desmatamento ligadas indissociavelmente, por um lado, a novas institucionalidades que garantam a distinção de direito entre ativos específicos e públicos representados pelos biomas amazônicos e os ativos genéricos e privados garantidos pela propriedade da terra; por outro, a políticas de produção - a ser operadas por mecanismos que façam convergir as decisões dos agentes com perspectivas macro de desenvolvimento: local (espacialmente configurada), endógeno (culturalmente enraizado) e sustentável (amparado em conhecimento que permita usar a base natural da Região sem depredá-la). Afortunadamente, as mais recentes proposições de políticas condensadas nos chamados REDD+ e REDD++ incorporam notavelmente essa percepção (Conf. Angelson, Brown, Lpisel, Peskett, Streck, Zarin, 2009).

\section{Referências}

Angelson, B., Brown, S., Lpisel, C., Peskett, L., Streck, C., Zarin, D. (2009). Reducing Emissions from Deforestation and Forest Degradation (REDD): An Option Assessment Report. Prepared for The Government of Norway, Meridien Institut.

Almeida, C.O., Caldas, R. C., Souza, D. M. O. Renda Familiar e Perspectivas de Crescimento da Demanda de Frutas Tropicais em Regiões Metropolitanas do Norte e Nordeste do Brasil. Brasília, Embrapa. S.d.

Cicas, G. (2005). Regional Economic Input-Output Analysis-Based Life-Cycle Assessment. Doctoral Thesis. Department of Civil and Environmental Engineering, Carnegie Mellon University, Pensylvania.

Costa, F. de A. (2009a). Dinâmica Agrária e Balanço de Carbono na Amazônia. In: EconomiA V. 10, n. 1, p. 117-151, Brasília, ANPEC, jan./mar. 2009.

Costa, F. de A.(2009b). Balanço de Carbono e Economia Local: Um Ensaio sobre uma Região Crítica da Amazônia. In: EconomiA, V. 10, n. 2, p. 299-332, Brasília, ANPEC, mai./ago. 2009.2.

Costa, F. de A. (2009c). Desenvolvimento agrário sustentável na Amazônia: trajetórias tecnológicas, estrutura fundiária e institucionalidade In: Um projeto para a Amazônia no Século 21: desafios e contribuições. 1 ed. Brasília: Centro de Gestão e Estudos Estratégicos, 2009.

Costa, F. de A. (2009d). Trajetórias Tecnológicas como Objeto de Política de Conhecimento para a Amazônia: uma metodologia de delineamento. In: Revista Brasileira de Inovação. Rio de Janeiro, FINEP, V. 8, n. 1, p. 35-86, jan./jun. 2009.

Costa, F. de A. (2008). Corporação e economia local: uma análise usando Contas Sociais Alfa (CS $\left.{ }^{\alpha}\right)$ do programa de investimentos da CVRD no Sudeste Paraense (2004 a 2010). In: Nova Economia, Belo Horizonte, 18 (3), p. 429-470, setembro-dezembro de 2008.

Costa, F. de A. (2007). A Questão Agrária na Amazônia e o Desafio Estratégico de um Novo Desenvolvimento. In: Becker, B., Costa, W. M. Da, Alves, D. S. (Orgs.) Dimensões Humanas da Bioesfera-Atmosfera na Amazônia. São Paulo, Edusp. Pp. 129-166.

Costa, F. A. (1995a). O Investimento Camponês: Considerações Teóricas. In: Revista de Economia Política. São Paulo: v.15, n.1, p.83 - 100 .

Diniz, C. C., Lemos, M. B. (2005). Economia e Território. Belo Horizonte, Ed. UFMG.

Fujita, M., Krugman, P., Venables, A. J. Economia Espacial: urbanização, prosperidade e desenvolvimento humano no mundo. São Paulo, Futura, 2002.

Grieg-Gran, M. (2006). The cost of avoid deforestation - report prepared for stern review, International Institute for Environment and Development. 
Gianbiagi, F. A Política Fiscal do Governo Lula em Perspectiva Histórica Qual é o aumento do gasto público? In: Planejamento e Políticas Públicas. N. 27, jun./dez. 2004-Brasília: Instituto de Pesquisa Econômica Aplicada, pp. 5-60

Guilhoto, J., Sonis, M., Hewings, G.J.D. Linkages and Multipliers in a Multirregional Framework: integrations of alternative approaches. University of Illinois, Regional Economics Applications Laboratory. 1997. (Discussion Paper, 97-T-2).

Stern, N. (2007). The Economics of Climate Change: The Stern Review. Cambridge, Cambridge University Press.

Hirschman, A. (1958). The Strategy of Economic Development. New Haven, Yale University Press.

Haddad, P. R.(1989a). Análise de insumo-produto regional e inter-regional, multiplicadores de produção, de renda e de emprego. In: Haddad, Paulo R. Economia Regional: Teorias e Métodos de Análise. Fortaleza: BNB-ETENE, 1989.

IBGE. Base de Informações Municipais. CD-ROOM.

IBGE. Censo Agropecuário 1995-96. CD-ROOM.

IBGE (1998). Censo Agropecuário do Estado do Pará 1996-96. CD-ROM.

IBGE (2001). Contas Regionais do Brasil. CD-ROM.

IBGE. Produção Agrícola Municipal (PAM), 1995 a 2005. (Sistema SIDRA).

IBGE. Pesquisa Anual de Comércio (PAC), 1995 a 2004.

IBGE. Pesquisa Anual de Serviços (PAS) 1995 a 2004.

IBGE. Pesquisa Industrial Anual (PIA),1996 a 2004.

IBGE. Pesquisa da Indústria da Construção Civil (PICC), 1995 a 2005.

IBGE. Produção Extrativa Vegetal (PEV), 1995 a 2005. (sistema SIDRA).

IBGE. Pesquisa Pecuária Municipal (PPM), 1995 a 2005. (sistema SIDRA).

IPEADATA. Preços, 1995 a 2005.

BRASIL-MTE - Relação Anual de Informações Sociais (RAIS), 1995 a 2005. (sistema de recuperação de estatísticas do emprego).

IBGE. Pesquisa do Orçamento Familiar (POF).

Isard, W. (1956). Location and Space-Economy: a general theory relating to spacial location, market areas, land use, trade and urban structure. Cambridge, M.I.T.

Isard, W. (1996). Methods of Regional Analysis. Cambridge, Mass, cap. XI.

Krugman, P. Development, Geography an Economic theory. Cambridge, The MIT Press.

Leontief, W. (1983). A Economia do Insumo-Produto. São Paulo: Abril Cultural, 1983.

Menezes, T., Silveira, F. G., Diniz, B. P. C. Elasticidade Renda dos produtos alimentares no Brasil e Regiões Metropolitanas: uma aplicação dos micro-dados da POF 1995/96. IPEA-USP, s.d.

Murray, B., MCCARL, C. A., Lee, H. C. "Estimating Leakage from Forest Carbon Sequestration Programs." Land Economics 80(1):109-124, 2004.

Myrdal, G (1957). Economic Theory and Underdeveloped Regions. London, Duckwoth.

Nepstad, D. C., Stickler, C. M., Almeida, O. T. (2008). Globalização das Indústrias de Soja e de Gado na Amazônia: Oportunidades para Conservação. In: Rivero, S. e Jayme Jr., F. G. As Amazônias do Século XXI. Belém, Ed. da UFPa, p. 41-67.

Polanyi, K. (1994). La gran transformación: las orígenes políticos e económicos de nuestro tiempo. Cidade do México, Fondo de Cultura.

Perroux, F. (1965). L'Economie du XXeme siécle. Paris, Presses Universitais de France.

Siqueira, R. B. De, Nogueira, J. R., Souza, E. S. A (2001). Incidência Final dos Impostos Indiretos no Brasil: Efeitos da Tributação de Insumos. In: Revista Brasileira de Economia, Rio de Janeiro, 55(4):513-544 out./dez.

Veiga, J. E. (2007). Amazônia, entre ladainha e pacto. In: Valor, 13.12.2007.

Vilela, P. S., Castro, C. W., Avellar, S.O.C. Análise da Oferta e da Demanda de Frutas Selecionadas no Brasil para o Decênio 206/2015. Belo Horizonte, FAEMG, s.d.

Young, C. E. (2007). Fundamentos econômicos da Proposta de Pacto Nacional pela Valorização da Floresta e pelo fim do Desmatamento na Floresta Amazônica. São Paulo, Macrotempo Consultoria. 